Now that the war is over, cannot some appeal be made to remedy this state of things? Is it too much to hope that a chair for ethnology might be endowed by private benefaction for the new teaching University of London, or at least that subscriptions might be secured sufficient to place the existing lectureships in Cambridge on a sounder and more satisfactory basis?

ANTHROPOTAMIST.

\section{Phosphorus versus Lime in Plant Ash.}

THAT in the mineral constituents of leaves a strong proportion of lime is an obstacle to the presence of a considerable quantity of potass has been recognised as a feature of calcifugous species of plants. It has been sought, indeed, to explain, apparently on this ground alone, the existence of special plants which shun lime soils, or at least to account for the difference between their habitat and that of calcicolous species. A certain proportion of lime in the soil, say about 12 per cent. carbonate, is sufficient for the needs of a certain number of calcicolous species and banishes the calcifugous species from it. If, however, we carefully examine the ash constituents of the leaves of herbs growing and seeding in a soil (such as here in this valley) with only about I per cent. lime $(\mathrm{CaO})$ in its finer particles, we recognise a large ratio both of potass and of lime, as the annexed table will attest.

\begin{tabular}{|c|c|c|c|c|c|}
\hline \multirow{2}{*}{ Leaves of } & \multirow{2}{*}{ Date. } & \multirow{2}{*}{$\begin{array}{l}\text { Per- } \\
\text { cent- } \\
\text { age of } \\
\text { Ash. }\end{array}$} & \multicolumn{3}{|c|}{$\begin{array}{c}\text { Constituents of the } \\
\text { Ash. }\end{array}$} \\
\hline & & & $\begin{array}{l}\text { Soluble } \\
\text { Salts. }\end{array}$ & CaO. & $\mathrm{P}_{2} \mathrm{O}_{5}$ \\
\hline 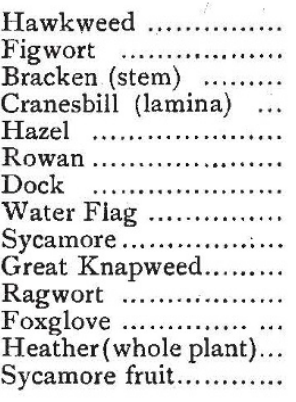 & 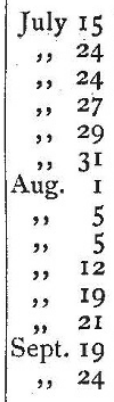 & $\begin{array}{l}12 \cdot 6 \\
8 \cdot 9 \\
- \\
7 \cdot 5 \\
6 \cdot 3 \\
6 \cdot 3 \\
11 \cdot 7 \\
8 \cdot 7 \\
10 \cdot 5 \\
10 \\
12 \cdot 2 \\
9 \cdot 1 \\
2 \cdot 2 \\
5 \cdot 5\end{array}$ & $\begin{array}{l}24 \cdot 7 \\
31 \cdot 7 \\
63 \cdot 8 \\
38 \cdot 3 \\
18 \cdot 3 \\
38 \cdot 5 \\
43 \cdot 4 \\
42 \cdot 2 \\
33 \cdot 6 \\
37 \cdot 1 \\
44 \cdot 5 \\
40 \cdot 7 \\
25 \\
37\end{array}$ & $\begin{array}{r}28^{\circ} \cdot 4 \\
24^{\circ} 7 \\
4 \cdot \mathrm{I} \\
24^{\circ} 9 \\
30^{\circ} 4 \\
23 \\
20 \\
29 \\
25^{\circ} 7 \\
29^{\circ} 4 \\
23^{\circ} 7 \\
25^{\circ} \cdot 3 \\
16 \cdot 3 \\
25^{\circ} 7\end{array}$ & $\begin{array}{l}4 \cdot 3 \\
8 \cdot 35 \\
3 \cdot 04 \\
9 \cdot 5 \\
7 \cdot 7 \\
5 \cdot 6 \\
6 \cdot 3 \\
6 \\
4 \cdot 7 \\
3 \cdot 6 \\
5 \cdot 15 \\
5 \\
7 \cdot 3 \\
8\end{array}$ \\
\hline
\end{tabular}

These figures are taken from my own analyses, the percentages being calculated on the crude ash minus charcoal. The sphere of experimental observation is, perhaps, too narrow or restricted, but a suspicion is awakened by the results that the need for phosphorus is a direct or indirect agent operative in the case. That is to say, a strong proportion of lime in the ash seems rather an auxiliary or accompaniment than an obstacle to a strong pro. portion of potass (as computed by the soluble salts). On the other hand, we see a rough approximation to an inverse ratio between the lime and the phosphorus, i.e. roughly 28 or 29 per cent. of lime with 3 or $4 \mathrm{P}_{2} \mathrm{O}_{5}$, and 23 or 24 lime with 8 or 9 $\mathrm{P}_{2} \mathrm{O}_{5}$; and where this does not prevail, the whole percentage of ash is below the average (as in water flag and the woody plants). That a poor yield of certain plants on calcareous soils appears to be due to the effect of the lime in preventing the assimilation of phosphorus is a result of the experiments of MM. Dehérain and Demoussy. Moreover, it is known that the ash of seeds, which is invariably very rich in phosphorus, contains also a comparatively very small proportion of lime. It would seem, therefore, to be legitimate to conclude that a certain proportion of lime in the soil (say 3 or 4 per cent.) is inimical to the life of certain plants which require a definite amount of phosphoric acid for the healthy performance of their physiological functions. The fact that some plants will grow, but not flourish or propagate; in certain localities or habitats is a pretty certain indication that a sufficient amount of phosphorus is not available to the seed for purposes of germination and development. The analyses would seem to indicate that a too liberal supply of lime is the preventa. tive agent in the case.

Patterdale, Westmorland.

P. Q. KEEGAN.

\section{ALUMINIUM AND ITS ALLOYS.}

$\mathrm{THE}$ electrolytic process for the extraction of aluminium, which was patented in 1887 by Héroult in Europe and by Hall in America, has resulted in such a great diminution in the cost of production that the price of the metal has fallen from about twenty shillings to one shilling a pound. It is not surprising that, in the early days of the electrolytic industry, this circumstance, combined with the many very valuable properties of aluminium, caused extravagant hopes for its future to be raised.

The experience that has been gained in the past five or ten years has enabled us to form a truer estimate of the value of the metal, though it would be difficult to say even now to how great an industrial importance it may ultimately develop. A very good idea of the present position and prospects of the industry may be obtained from two papers recently published in the Journal of the Institution of Electrical Engineers. ${ }^{1}$ The first of these, by Prof. E. Wilson, gives the results of an elaborate series of tests of the physical properties of a number of aluminium alloys; we shall have occasion to refer to this paper later. The second paper is by Mr. W. Murray Morrison, and contains a description of the British Aluminium Company's works at Foyers and an account of the applications of the metal, its use as an electrical conductor being considered at some length. We are enabled by the courtesy of the British Aluminium Company to give an illustration showing the turbogenerators in the power-house at Foyers.

The Hall and Heroult processes for the electrolytic extraction of aluminium are practically identical and are too well known to need lengthy description. The aluminium is obtained as the result of the electrolysis of alumina dissolved in melted cryolite $\left(6 \mathrm{NaF} \cdot \mathrm{Al}_{2} \mathrm{~F}_{6}\right)$. The electrolysis is carried out in a carbon-lined crucible, at the bottom of which the separated metal collects, the liberated oxygen combining with the carbon of the anode and passing off ultimately as carbon dioxide. It is interesting to note that, whereas the specific gravity of solid aluminium is less than that of solid cryolite, in the fused condition this order is reversed; but for this the process in its present form would be unworkable. Some figures showing the cost of production by the Héroult process are given by Mr. Blount in his "Practical Electrochemistry," as follows :-

\begin{tabular}{|c|c|c|c|c|}
\hline Cost of power & $\ldots \quad 2 \cdot 2$ & nce & . $\mathrm{c}$ & minium. \\
\hline Cost of alumina & $\ldots 44^{\circ}$ & $\therefore$ & " & \\
\hline Cost of electrodes & $\ldots \quad 2 \cdot 0$ & ,", & " & , \\
\hline Cost of labour, \&c. & $\ldots \quad 2^{\circ} 0$ & ", & ", & ," \\
\hline & & ", & ," & " \\
\hline
\end{tabular}

It is probable that this estimate is somewhat high, but it is sufficient to show that the cost of power is a very important item, which explains the necessity for the use of water-power. The cost of power per lb. is higher than in any other electrolytic manufacture; it forms, it will be seen, about one-fifth of the total cost; in the manufacture of calcium carbide, another electrochemical industry requiring cheap power, the ratio of cost of power to total cost is about 1 to $7^{\circ} 5$.

The product of the electrolytic furnace is very pure. According to Mr. Morrison, commercial aluminium is $99^{\circ} 5$ to $99^{\circ} 6$ per cent. pure, the impurities being iron (about 0.25 per cent.) and silicon (about 0.17 per cent.). A sample of pure commercial aluminium analysed by Prof. Wilson contained $0^{\prime} 3 \mathrm{I}$ per cent. $\mathrm{Fe}$ and $0^{\circ} \mathrm{I} 4$ per cent. $\mathrm{Si}$, which agrees pretty closely with $\mathrm{Mr}$. Morrison's figures.

1 "The Physical Properties "of certain Aluminium Alloys, and some Notes on Aluminium Conductors," by Prof. E. Wilson. (Journal I.E.E. vol. xxxi. p. 32r.) "Aluminium: Notes on its Production, Properties and Use," by W. Murray Morrison. (Ibid. p. 400.)

No. I722, VOL. 66] 
This standard of purity has only been gradually attained, and we may hope for further improvement. The purity is a matter of importance, as it affects the value of the metal as an electrical conductor in two ways, for impurities not only lower the conductivity, but also increase the liability to atmospheric corrosion. The evidence as to the power of aluminium to withstand atmospheric influences, especially in towns or places where the air is bad, is somewhat conflicting, but on the whole it seems that the metal is fairly satisfactory in this respect. The thin film of oxide which immediately forms on the surface of the metal in air acts as a protective coating. Mr. Morrison quotes an interesting illus-

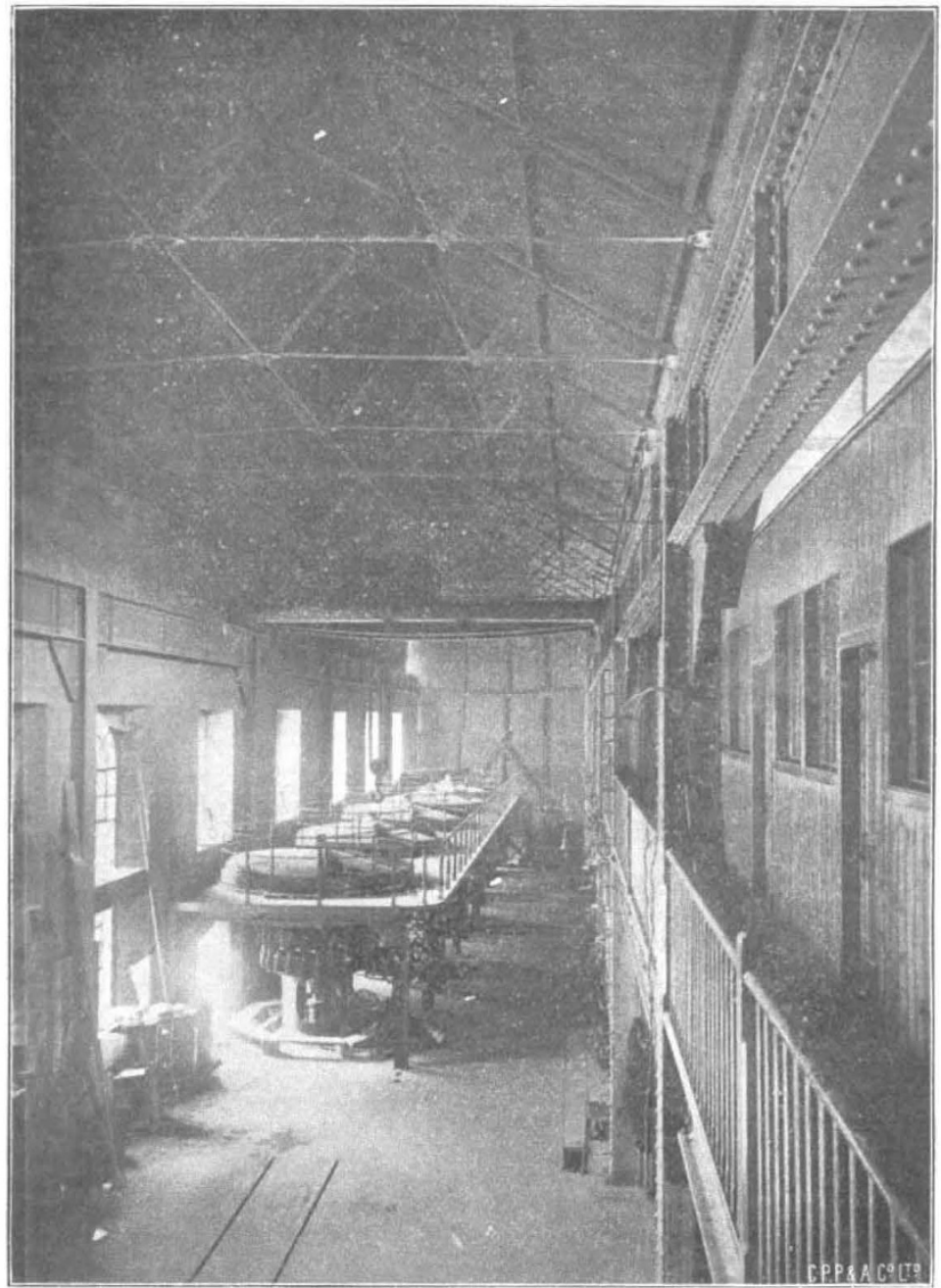

Fig. I.-The British Aluminium Company's Power-house at Foyers.

per ton, of aluminium is found greatly to improve the finished casting ; the aluminium, by combining with the occluded gases, reduces the blowholes and renders the metal being cast more fluid and ultimately more homogeneous. Though the actual quantity used in this way is but a small percentage of the metal to which it is added, the total consumption of aluminium for this purpose is very large. A second use for aluminium depending on the same principle has been devised by Dr. Goldschmidt for producing high temperatures, and has been applied to the welding of iron rails, pipes and so forth. A mixture of iron oxide and finely divided aluminium is used, and is ignited by means of a magnesium ribbon; a very high temperature is immediately reached by the oxidation of the aluminium at the expense of the oxygen of the iron oxide. This process, having been only lately introduced, has not yet becorne of much commercial importance, but is full of promise.

The extremely low specific gravity $\left(2^{\circ} 6\right)$ of aluminium has naturally resulted in its use in cases in which weight is a drawback. Thus in naval and military equipments, in motor-car construction and like applications, the metal already finds considerable and increasing employment. For cooking utensils the use of aluminium is steadily increasing; the metal is eminently suited for this purpose, as, apart from its lightness, it is a good conductor of heat, is not liable to deteriorate in use and gives rise, if dissolved, to perfectly harmless compounds. Applications of this kind may seem small individually, but in the aggregate they constitute no mean field for the metal to capture.

The chief drawback to aluminium is its low tensile strength, which, for the cast metal, is only from five to eight tons per square inch; but for this weak. ness its utility would be enormously increased. A certain amount of improvement can be effected by alloying a small quantity, generally less than ro per cent., of some other metal, such as nickel or copper, with the aluminium. The specific gravity of these alloys is only slightly higher than that of the metal itself, but the tensile strength may be made two or three times as great. Exceedingly valuable data relating to a number of these light alloys are contained in the paper by Prof. Wilson to which reference has been made above. It is impossible to enter at all fully into the results obtained by Prof. Wilson, as the paper is itself so condensed as to be little more than a summary, but a few of the more interesting conclusions may be briefly tabulated. In the accompany-

tration of the tenacity of this oxide film; if the metal is cast into a mould and allowed to overflow, the film of oxide adhering to the molten metal that has run over acts as a syphon tube, and will syphon out a considerable quantity of the aluminium.

The two most marked characteristics of aluminium, on which its principal applications depend, are its high affinity for oxygen and its low specific gravity. The former of these properties causes aluminium to play a part of considerable importance in the metallurgy of other metals. Thus in the casting of steel, iron, brass, \&c., the addition of a small quantity, two to five pounds ing table is shown approximately the effect of alloying different metals on the conductivity, specific gravity and strength of aluminium.

Aluminium is now finding considerable employment as a substitute for copper as an electrical conductor, especially in America, where it is used to a large extent in connection with the transmission of power over long distances. One of the most important of these installations is the transmission of 12,000 h.p. from the Snoqualmie Falls to Seattle and Tacoma, a distance of more than forty miles. In this scheme an alloy of aluminium with $I \frac{1}{2}$ per cent. of copper has been used, the lightness

No. 1722 , vor. 66$]$ 


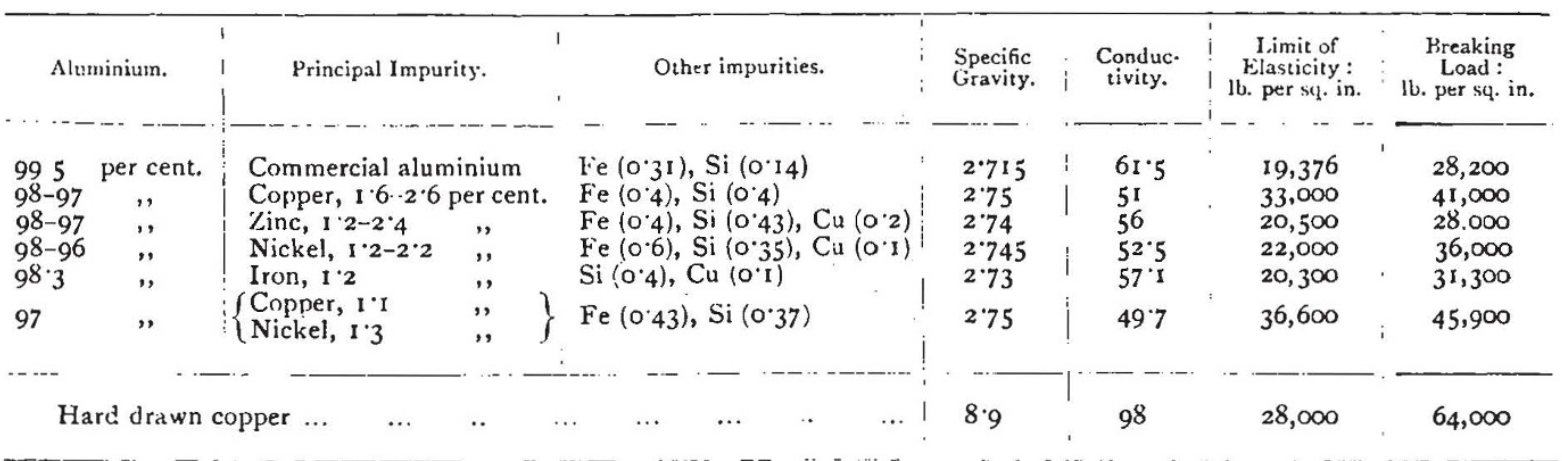

and strength of this alloy enabling spans of I 50 feet to be made with safety. A great saving in the number of poles is thus effected, which is one of the principal advantages gained. Numerous other important transmission schemes might be quoted in which aluminium is used, or in which it has been decided to use it. As has been just pointed out, the use of aluminium effects a great saving in the number of poles required; it also involves dealing with a much smaller weight of conductor, and is, finally, cheaper than copper. In round numbers, for equal conductivity, the section of an aluminium cable is one and a half times that of a copper one, the weight is half and the tensile strength three-quarters. It is the decreased weight which, in spite of the smaller tensile strength, allows longer spans to be used, and this effect can be made more marked by the use of a suitable alloy possessing increased strength without much diminished conductivity or much higher specific gravity. Mr. Morrison gives an interesting table showing the variation, according to the price of copper, in the price per lb. that can be paid for aluminium for equal conductivity and equal cost. From this it appears that with copper at its present price of about tenpence per Ib., twenty-one pence per lb. could be paid for aluminium, which is two or three pence above its market price, showing that aluminium conductors are cheaper.

It is to be noted that the above remarks apply only to bare conductors. Where insulated cables are needed for low-tension work the increased diameter of an aluminium conductor involves increased cost in insulating material ; moreover, with lead-covered cables the increased weight of the lead would almost, if not quite, cancel the decrease in weight gained by substituting aluminium for copper. For high-tension cables it is possible that aluminium may in some cases be cheaper than copper. Thus in a paper by Mr. M. O'Gorman ${ }^{1}$ it is shown that increasing the diameter of the conductor may produce such a diminution in the depth of insulation necessary as to lessen the total price ; in such circumstances a tubular copper conductor, or an aluminium conductor, could be used with advantage. There seems, therefore, a possibility that aluminium may some day successfully invade the field of insulated cables, hitherto regarded as pecu. liarly the property of copper.

M. S.

\section{RECENT WORKS ON SYSTEMATIC BOTANY IN GERMANY.}

I T was in the year $\mathrm{I} 887$ that, following on the publisher's announcement, the first parts of "Die natürlichen Pflanzenfamilien" appeared under the joint editorship of Drs. Engler and Prantl. The announcement does not seem to have attracted much attention, as there was no mention of it in many botanical journals until several numbers following each other rapidly came under notice. Strange as it may seem, De Bary's name does not appear as one of the collaborators, nor did he have any share in

1 "Insulation on Cables," by Mervyn O'Gorman. (Journal of the Institution of Electrical Engineers, vol. xxv. p. 608.$)$

No. I 222 , vOL. 66$]$ the work. His remarks, therefore, as set forth in Die Botanische Zeitung in October, 1887 , besides providing a criticism of the general scheme, also enable one to form an idea of the attitude displayed towards the undertaking.

He says, "the object is to present by means of illustrations and descriptions a corporate picture of the plant world which shall be strictly scientific and at the same time generally intelligible. Under each family, and for each genus of that family, mention will be made of any. points that call for description or that have a practical bearing."

That there was some uncertainty as to its successful completion may be gathered from what he says later, after congratulating editor and publisher:-

"If the book is only carried through as it has been started, then it will have no equal ... since it gives in. formation shortly and objectively, not in the abstruse and learned manner of Bentham and Hooker, nor yet in the form of the subjectively learned monograph touched up with popular varnish which characterises the otherwise life-like history of plants by Baillon." Undoubtedly the terse and vigorous descriptions, the careful choice of matter, and the wealth of illustration which elicited favourable comment for the earlier numbers have, on the whole, been consistently maintained. Now that the work is almost completed, and as one looks back on the enormous labour entailed, congratulations may again be offered to Dr. Engler, who has been the sole editor since Dr. Prantl died in 1893 .

The responsibility of such a vast undertaking might well be sufficient, but in the year $1900 \mathrm{Dr}$. Fngler announced the publication of a new work, "Das Pflanzen. reich"-adopting the title suggested by De Bary-which will amplify the information given in "Die naturlichen Pflanzenfamilien." As Dr. Engler announces in his introduction, "Das Pflanzenreich" is not a revised edition of "Die natürlichen Pflanzenfamilien," for appendices to the latter will continue to appear fron time to time, and whereas "Die Pflanzenfamilien" gives a complete account of the orders and genera, but only enumerates a few species, "Das Pflanzenreich" will furnish a full and comparative account of all authenticated species.

Eleven parts have already been issued --" Musacex," by K. Schumann ; "Typhacex and Sparganiacea," by P. Graebner; "Pandanaceæ," by O. Warburg; "Monimiaceæ," by J. Perkins and E. Gilg ; "Rafflesiaceæ and Hydnoracex," by H. Graf zu Solms Laubach ; "Symplocace:e," by A. Brand ; "Naiadacex," by A. B. Rendle ; "Aceraceæ," by F. Pax ; "Myrsinaceic," by C. Mez; "Tropxolacex," by Fr. Buchenau ; and "Marantaceæ," by K. Schumann.

As regards the general arrangement, the citation of important literature and the review of the main characters of the order are similar to the method adopted in "Die Pflanzenfamilien," and, together with a certain number of illustrations, will be more or less the same. 13ut, apart from new facts which may be added, it will be observed that the orders are not necessarily taken up by the same authors in the two works. English botanists may be 